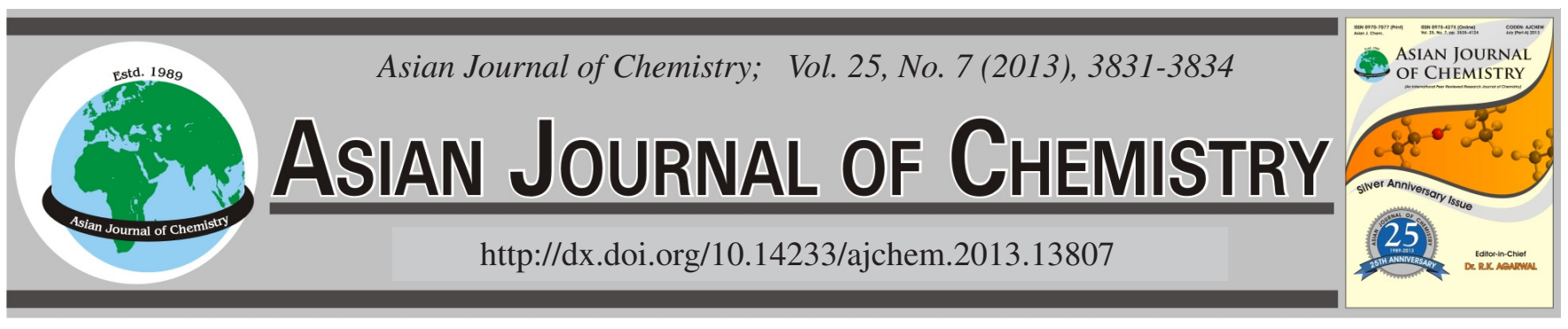

\title{
Study on Glass Fiber/Epoxy Gradient Damping Composites
}

\author{
Hong Zhen ${ }^{1, *}$, WAng XIANG ${ }^{2}$, XiE XIAO-Lin ${ }^{1}$, Li Zhi-Peng ${ }^{1}$ and WAn Li-Ying ${ }^{1}$
}

${ }^{1}$ School of Materials Science and Technology, Nanchang Hangkong University, Nanchang 330063, P.R. China

${ }^{2}$ School of Materials Science and Technology, Wuhan University of Technology, Wuhan 430070, P.R. China

*Corresponding author: E-mail: zhenhong717@163.com

\begin{abstract}
A kind of composites was prepared by pre-impregnated-hand lay-up process that each glass fabric impregnated by epoxy resin of different damping properties was placed in different layer. The damping properties of composites were studied by dynamic thermomechanical analysis (DMA). The results show that the gradient loss peak in loss factor-temperature spectrum of composites shows this kind of composites have gradient damping effect, which reaches a kind effect of broadening the effective damping temperature range. The effective damping temperature range of glass fabric/epoxy-matrix gradient damping composites reaches $34.5^{\circ} \mathrm{C}$, the loss factor is 0.516 , | the glass transition temperature $\left(\mathrm{T}_{\mathrm{g}}\right)$ is $23.6^{\circ} \mathrm{C}$, the composites have higher damping properties at $13.2-47.7^{\circ} \mathrm{C}$. It is more conducive to use the epoxy resin with best damping properties in the middle layer to improve damping properties of composites at room temperature.
\end{abstract}

Key Words: Epoxy-matrix composites, Gradient damping, Effective damping temperature range, Loss factor, Glass transition temperature.

\section{INTRODUCTION}

Usually composite materials, prepared using single common epoxy resin as matrix material, have large brittleness and poor damping properties. For example, the damping factor of glass fiber reinforced epoxy composites is 0.3 or so, the glass transition temperature $\left(\mathrm{T}_{\mathrm{g}}\right)$ reaches up to $50{ }^{\circ} \mathrm{C}$, the effective damping temperature range is only $15^{\circ} \mathrm{C}^{1}$. This doesn't meet the application requirements for epoxy-matrix composites as damping materials at the aspect of noise and vibration reduction at room temperature and the temperature or frequency range of damping materials experienced in practical applications often tends to be relatively wide ${ }^{2}$.

Compared with the macro-homogeneous materials, the gradient materials have the characteristics that the composition and structure change in control continuously and gradient in the direction of thickness, density, etc. Accordingly, the comprehensive performance of materials can be improved by material gradient design ${ }^{3,4}$. In the preparation of composite materials, different epoxy as matrix is placed in different fiber plies, because of these epoxy matrixes of different damping properties, the damping properties of composite materials change continuously and gradient in the thickness.

It shows a trend that damping peaks of composites move closer to each other, the damping peak areas and widths increase overall, the peak temperature moves toward the actual use of temperature of damping materials, so that the epoxy-matrix composites achieve the application requirements of damping materials ${ }^{5-7}$. Therefore, glass-fiber reinforced epoxy composites were prepared using the pre-impregnated - hand lay-up method in this study. The dynamic mechanical properties were tested by dynamic thermomechanical analysis (DMA), the impact of resin matrix and layer approach on the damping properties of the epoxy composites was studied, epoxy-resin gradient damping composites with better damping properties at room temperature were found.

\section{EXPERIMENTAL}

According to the ratio in Table-1, epoxy CYD128 (biphenyl type, epoxy value 0.51 , Sinopec Baling Petrochemical) was mixed with epoxy XY678 (neopentyl glycol diglycidyl ether, epoxy value 0.65, Anhui Xinyuan Chemical) evenly, then the mixed epoxy resin system was added with curing agent amino-terminal polyamine D400 and D2000 (Huntsman Corporation), mixed thoroughly and excluded the air bubbles. The prepreg was fabricated from single-layer glass fabric (FW811, thickness 0.4 mm, Nanjing Fiberglass Research and Design Institute) impregnated with this curing system by the hand lay-up method. It was aired to reach the gel state at room temperature and numbered sequentially as G1, G2 and G3.

All the gradient damping composite specimens were fabricated from prepreg cloth placed in the corresponding overlay 
TABLE-1

TABLE OF THE CURING SYSTEM MIXED RATIO

\begin{tabular}{ccccc}
\hline \multirow{2}{*}{ Number } & \multicolumn{4}{c}{ Usage (copies of percentage quality) } \\
\cline { 2 - 5 } & CYD128 & XY678 & D400 & D2000 \\
\hline$\# 1$ & 100 & - & 55 & - \\
$\# 2$ & 70 & 30 & 60 & - \\
$\# 3$ & 70 & 30 & 60 & 10 \\
\hline
\end{tabular}

location and bonded with epoxy \#3 by hand lay-up method, the specific stacking sequence was shown in Table-2. The glass fiber prepreg layer was designed to make the damping properties of the epoxy matrix along the fiber layer in the gradient distribution of state. The number of layers was set to 3 layers. After gelled at room temperature, they were cured $2 \mathrm{~h}$ at $60^{\circ} \mathrm{C}$ and then $2 \mathrm{~h}$ at $100^{\circ} \mathrm{C}$. The composite specimens were cut of bending specimens according to the DMA testing standards and numbered as shown in Table-2. The gradient damping composite structure was shown in Fig. 1. At the same time, the blank specimens were prepared with the three kinds of epoxy resin cured system as resin matrix respectively, numbered for the $\mathrm{G}_{111}, \mathrm{G}_{222}$ and $\mathrm{G}_{333}$.

TABLE-2

OVERLAY DESIGN OF GRADIENT DAMPING COMPOSITES

\begin{tabular}{cccc}
\hline Number & Overlay mode & Inter-laminar resin & Layers \\
\hline $\mathrm{G}_{123}$ & G1-G2-G3 & $\# 3$ & 3 \\
$\mathrm{G}_{132}$ & G1-G3-G2 & $\# 3$ & 3 \\
$\mathrm{G}_{213}$ & G2-G1-G3 & $\# 3$ & 3 \\
\hline
\end{tabular}
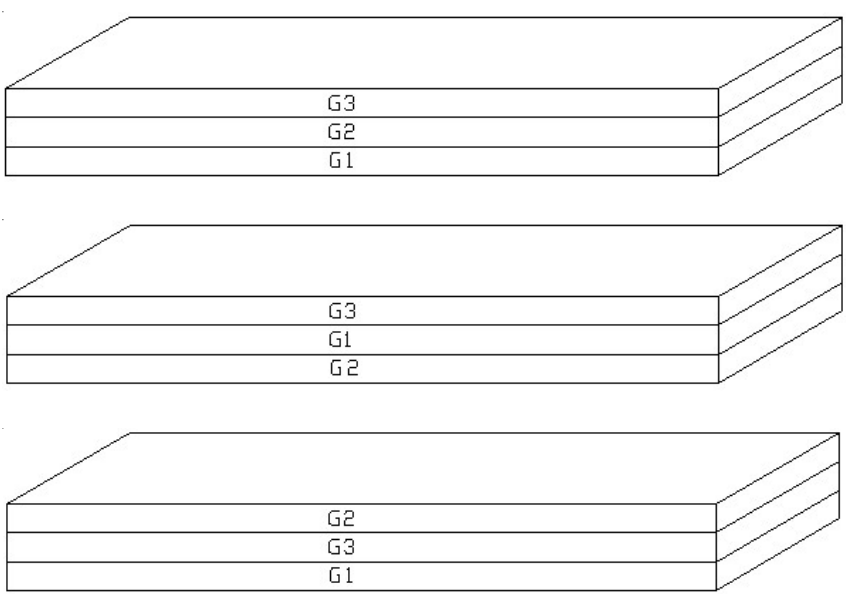

Fig. 1. Schematic diagram of gradient damping composites

The dimension of bending composite specimens was 50 $\mathrm{mm}$ long, $10 \mathrm{~mm}$ wide and $2 \mathrm{~mm}$ thick. The damping properties have been tested by adopting three-point bending mode by Pyris Diamond DMA from Perkin-Elmer Company, USA. The span is $20 \mathrm{~mm}$, the test frequency is $1 \mathrm{~Hz}$, the scanning temperature range is $-20-80{ }^{\circ} \mathrm{C}$, the heating rate is $2^{\circ} \mathrm{C} / \mathrm{min}$.

\section{RESULTS AND DISCUSSION}

Damping properties of different epoxy-matrix composites: The dynamic mechanical properties of composites $\mathrm{G}_{111}$, $\mathrm{G}_{222}$ and $\mathrm{G}_{333}$ have been investigated by DMA. The loss factortemperature spectrum has been shown in Fig. 2. As it can be seen from Fig. 2, compared with the composites $\mathrm{G}_{111}$, the composites $\mathrm{G}_{222}$ has been presented with the damping peak

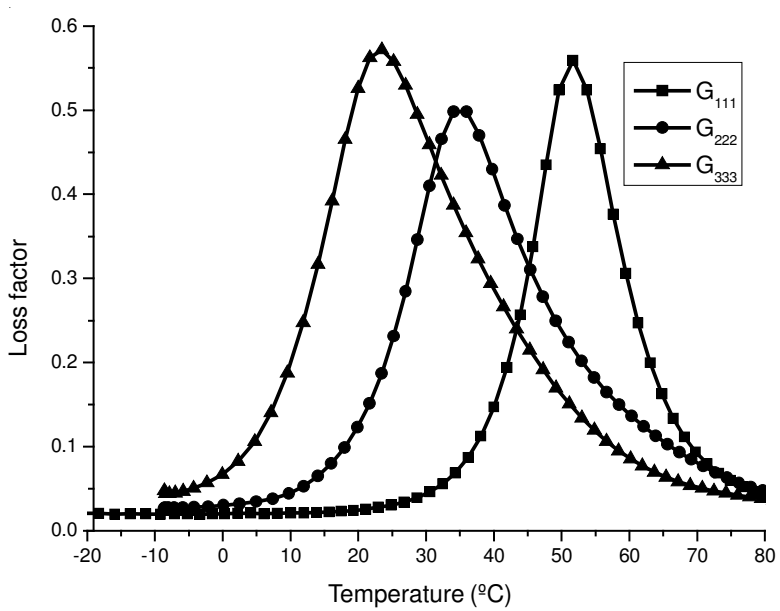

Fig. 2. Loss factor-temperature spectra comparison chart of ordinary composites

decreased, with the damping peak width increased and with the temperature corresponding to the peak reduced. In the three, for the composites $\mathrm{G}_{333}$, the damping peak was the biggest, the damping peak width was the widest and the temperature corresponding to the peak was the lowest, which showed the composites $\mathrm{G}_{333}$ of the best damping performance. The specific damping data can be seen in Table-3.

\begin{tabular}{|c|c|c|c|}
\hline \multicolumn{4}{|c|}{$\begin{array}{c}\text { TABLE-3 } \\
\text { DAMPING PROPERTIES OF ORDINARY COMPOSITES }\end{array}$} \\
\hline Number & $\mathrm{G}_{111}$ & $\mathrm{G}_{222}$ & $\mathrm{G}_{333}$ \\
\hline $\mathrm{T}_{\mathrm{g}}\left({ }^{\circ} \mathrm{C}\right)$ & 51.7 & 34.1 & 23.5 \\
\hline Maximum of loss factor $(\tan \delta)$ & 0.559 & 0.498 & 0.572 \\
\hline $\begin{array}{l}\text { Effective damping temperature } \\
\text { range }\left({ }^{\circ} \mathrm{C}\right)(\tan \delta \geq 0.3)\end{array}$ & 16.0 & 19.2 & 25.5 \\
\hline
\end{tabular}

According to Table-3, the $T_{g}$ of the composites $G_{222}$ (prepared using damping modified epoxy resin) compared to the composites $\mathrm{G}_{111}$ (prepared using damping unmodified epoxy resin) reduced from 51.7 to $34.1^{\circ} \mathrm{C}$, which was closer to the room temperature, the maximum loss factor was the lowest 0.498 among the three, the effective damping temperature range increased $3.2{ }^{\circ} \mathrm{C}$ than the composites $\mathrm{G}_{111}$. Compared with the composites $\mathrm{G}_{111}$, the damping performance of composite $\mathrm{G}_{333}$ prepared with damping modified epoxy resin increased significantly, the $\mathrm{T}_{\mathrm{g}}$ decreased from 51.7 to $23.5^{\circ} \mathrm{C}$, reaching to the room temperature within, the maximum loss factor increased from 0.559 to 0.572 and the effective damping temperature range raised from 16.0 to $25.5^{\circ} \mathrm{C}$, of $9.5^{\circ} \mathrm{C}$.

Because the reinforcements of the three kinds of composite materials were the same kind of glass fabric and the fiber content was basically the same through the tests, which showed the loss factor of composite materials change with the loss factor change of resin matrix. This can be deduced from the mixture rule of composites. Liao et al. ${ }^{8}$ have shown that the loss factor of composite materials would comply with the mixture rule, by the formula (1):

$$
\eta_{c}=\frac{\eta_{m}\left(1-V_{f}\right)+\frac{E_{f}}{E_{m}} \times \eta_{f} \times V_{f}}{1-V_{f}+\frac{E_{f}}{E_{m}} \times V_{f}}
$$


Among them, $\eta_{\mathrm{c}}, \eta_{\mathrm{m}}$ and $\eta_{\mathrm{f}}$ are the loss factor of the composites, the matrix resin and the fiber respectively, $\mathrm{E}_{\mathrm{m}}$ and $\mathrm{E}_{\mathrm{f}}$ are the elastic modulus of the resin matrix and the fiber respectively, $\mathrm{V}_{\mathrm{f}}$ is the fiber volume fraction in composites.

Since the loss factor of the epoxy resin matrix is far higher than the glass fabric, yet the modulus is much lower than the glass fabric. For a given epoxy resin, glass fabric and their volume fraction, the most effective way to raise the composite damping factor is to reduce the modulus between the fabric and resin and to raise the loss factor of resin and fiber. The fabric modulus $\mathrm{E}_{\mathrm{f}}$, fabric volume fraction $\mathrm{V}_{\mathrm{f}}$ and fabric loss factor $\eta_{\mathrm{f}}$ of three specimens $\mathrm{G}_{111}, \mathrm{G}_{222}$ and $\mathrm{G}_{333}$ were all the same and the modulus of three resin matrix were almost equal in the glassy state, the difference was the loss factor of the matrix used, experimental values were 1.31, 1.26, 1.43 followed by. According to formula (1), it showed that the composite mechanical loss factor was determined mainly by the loss factor of the resin matrix.

Damping properties of the gradient damping composites: The dynamic mechanical properties of composites $\mathrm{G}_{123}$, $\mathrm{G}_{132}$ and $\mathrm{G}_{213}$ have been investigated by DMA. The loss factortemperature spectrum has been shown in Fig. 3. As it can be seen from Fig. 3, the damping peak of the composites $G_{132}$ was closer to the low temperature, the temperature corresponding to the damping peak was the lowest, the damping peak width and the effective damping temperature area were all the highest, which showed the composites $\mathrm{G}_{132}$ of the best damping performance among the three. The damping peak of the composites $\mathrm{G}_{213}$ was closer to the high temperature, the temperature corresponding to the damping peak was the highest, the damping peak width and the effective damping temperature area were all the lowest and the loss factor was the lowest in the three, which showed the composites $\mathrm{G}_{213}$ of the worst damping properties. The specific damping data can be seen in Table-4.

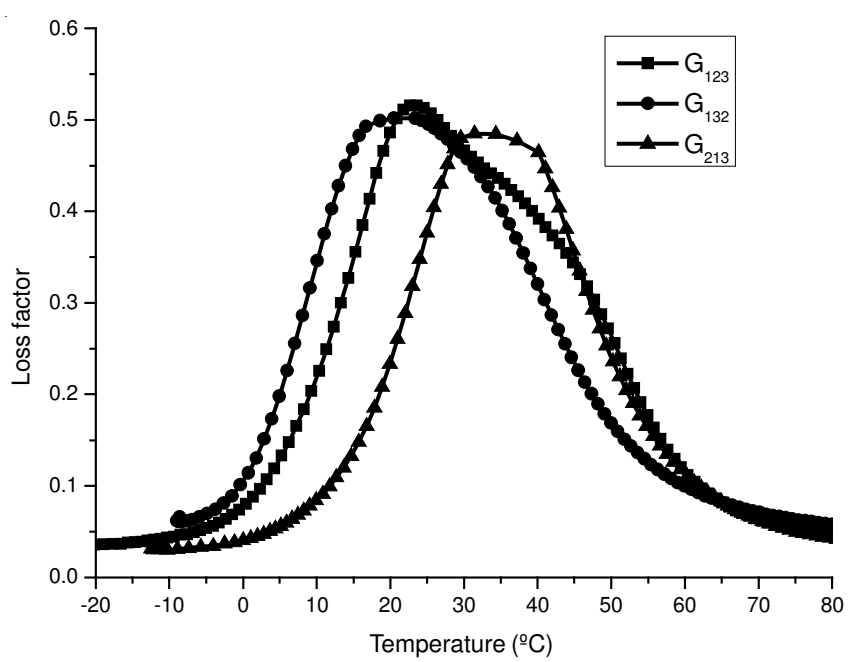

Fig. 3. Loss factor-temperature spectra comparison chart of gradient damping composites

It can be seen from Table- 4 that, the peak temperature of loss peak of the composites $\mathrm{G}_{132}$ was $23.4^{\circ} \mathrm{C}$, the maximum loss factor was 0.501 , the effective damping temperature range reached to $35.2{ }^{\circ} \mathrm{C}$. The peak temperature of loss peak of the

\begin{tabular}{|c|c|c|c|}
\hline \multicolumn{4}{|c|}{$\begin{array}{c}\text { TABLE-4 } \\
\text { DAMPING PROPERTIES OF } \\
\text { GRADIENT DAMPING COMPOSITES }\end{array}$} \\
\hline Number & $\mathrm{G}_{123}$ & $\mathrm{G}_{132}$ & $\mathrm{G}_{213}$ \\
\hline $\mathrm{T}_{\mathrm{g}}\left({ }^{\circ} \mathrm{C}\right)$ & 23.6 & 23.4 & 31.4 \\
\hline Maximum of loss factor $(\tan \delta$ ) & 0.516 & 0.501 & 0.485 \\
\hline $\begin{array}{l}\text { Effective damping temperature } \\
\text { range }\left({ }^{\circ} \mathrm{C}\right)(\tan \delta \geq 0.3)\end{array}$ & 34.5 & 35.2 & 24.5 \\
\hline
\end{tabular}

composites $\mathrm{G}_{213}$ was higher $31.4^{\circ} \mathrm{C}$, the maximum loss factor was 0.485 , less than 0.5 , the effective damping temperature range was only 24.5 and $10.7^{\circ} \mathrm{C}$ lower than the composites $\mathrm{G}_{132}, 10^{\circ} \mathrm{C}$ lower than the composites $\mathrm{G}_{123}$.

This indicates that the overlay position of fabric prepreg has effect on the damping properties of composite materials. In the composites $\mathrm{G}_{132}$, since the resin \#3 with better damping properties was in the position of the central axis, the overall damping performance was better. Yet in the composites $G_{213}$, since the resin \#3 with poor damping properties was in the position of the central axis, the overall damping performance was poor. In the composites $G_{123}$, since the resin \#2 with damping properties between the three kinds of epoxy resin was in the position of the central axis, the overall damping performance was between them. The reason is that, when the composite materials were suffered from vibration perpendicular to the composite sample, they subjected to bending stress, while the middle layer subjected to shear stress. When the epoxy resin with better damping properties was deposed in the middle layer, it may produce a larger deformation and consume more energy, thereby enhance the damping performance of the system as a whole. Thus, it can be more conducive to select better damping properties of resin system placed in the middle position to fabricate composite materials, to expand the effective damping temperature range, to improve the damping properties.

It can be seen from Figs. 2 and 3 comprehensively, compared to the three smooth curves of composites in Fig. 2, the loss peak of three kinds of composites, particularly the composites $\mathrm{G}_{123}$, obviously presented a mixture of multi-peak width peak in Fig. 3. Especially at the higher temperature section, there was some ladder-type transition. The two transition ladder appeared respectively in the vicinity of the peak temperature of the composites $\mathrm{G}_{111}$ and $\mathrm{G}_{222}$ and close to the low temperature, indicated that there was some certain gradient effect. The loss peak width significantly increased, the peak value and the peak temperature had little change compared to the best damping properties of the composites $G_{333}$, suitable for use in the normal temperature range. This indicated that the damping performance of composites can be improved if select fabric impregnated with three kinds of resin and laminated in turn to prepare gradient damping composite materials, compared with the preparation of a single resin composite materials. From Tables 3 and 4, the loss peak temperature of composite $\mathrm{G}_{123}$ was $23.6^{\circ} \mathrm{C}$, the loss factor was 0.516 and the effective damping temperature range improved up to $34.5,9$, 15.3 and $18.5^{\circ} \mathrm{C}$ higher than the composites $\mathrm{G}_{333}$, the composites $\mathrm{G}_{222}$, the composites $\mathrm{G}_{111}$ separately.

The content of resin \#3 as bonding materials was more in gradient damping composites $\mathrm{G}_{123}$. Because of different resin 
volume fraction occupied, their contribution to the damping properties of composite materials was not the same and the three peaks moved closer to each other, the peak temperature of the gradient composites $G_{123}$ closed to and was slightly higher than the peak temperature of the composites $\mathrm{G}_{333}$. The damping peak of the composites $\mathrm{G}_{333}$ appeared at $23.5^{\circ} \mathrm{C}$. The peak height corresponding to the resin \#1 and the resin \#2 lowered, appeared at 34.1 and $51.7^{\circ} \mathrm{C}$, respectively, which were close to the $T_{g}$ of the resin. The $T_{g}$ of the three kinds of resin closed to each other, the resin was changed from the glassy to the viscoelastic state in the process of temperature rise, thus forming a ladder effect. This enables the composite damping temperature range increases. The overall performance is that the loss factor increased step by step with the rising temperature. The nonlinear damping behaviour can play a role in the design of the damping properties of composite materials.

From the above-mentioned comparison of the gradient damping composite materials with the single resin composites, it can be seen that some gradient distribution may be formed in the fiber surface from the choice of three kinds of different resin, from placing resin systems of different $T_{g}$ and effective damping temperature range in different layers. When the composite material was subjected to stress which was passed to the fibers by the resin matrix, due to a larger deformation produced from the damping resin on the fiber surface, it plays a role of energy dissipation, an increase of the damping of the system, in order to broaden the effect of the damping peak.

\section{Conclusion}

If the type and the volume fraction of fiber are the same, the loss factor of composite materials was determined by the loss factor of the resin matrix. The damping properties of composites was improved effectively at room temperature if gradient damping composites was prepared using epoxy resin with different glass transition temperature, loss factor and effective damping temperature range as matrix by pre-impregnated-hand lay-up process. The effective damping temperature range of glass fabric/epoxy-matrix gradient damping composites reaches $34.5^{\circ} \mathrm{C}$, the loss factor is 0.516 , the glass transition temperature is $23.6^{\circ} \mathrm{C}$, the composites have higher damping properties at $13.2-47.7^{\circ} \mathrm{C}$. If the resin with better damping properties is in the middle layers, the overall damping properties of composite materials was improved since the middle layer suffered shear force can produce a larger deformation and consume more energy.

\section{REFERENCES}

1. H. Li, Polymer Composites, Beijing: China Light Industry Press (2008).

2. M.L. Guo, Dynamic Mechanical Thermal Analysis of Polymers and Composite Materials, Beijing: Chemical Industry Press (2002).

3. C.C. Zhang, F. Huang, L.L. Wei and L.L. Wu, J. Wuhan Univ. Technol., 10, 13 (2002).

4. J. Zhao, X. Ai and J.H. Zhang, Mater. Rev., 8, 57 (1997).

5. Z.X. Huang, M.X. Shi, G.R. Yang and Y.M. Li, Adhesion, 28, 47 (2007).

6. C.A. Qin, W.M. Cai and J. Cai, Mater. Chem. Phys., 85, 402 (2004).

7. Y.Z. Fan, K. Sun and R.J. Wu, J. Mater. Eng., 44, 29 (2000).

8. Y.Q. Liao, N. Du and Y. Cheng, Fiber Glass, 15 (2007). 